CERN-EP-2000-024

11 February 2000

\title{
DEFECT COMPLEXES FORMED WITH AG ATOMS IN CDTE, ZnTe, AND ZnSe
}

\author{
H. Wolf ${ }^{1}$, T. Filz ${ }^{1}$, V. Ostheimer ${ }^{1}$, J. Hamann ${ }^{1}$, S. Lany ${ }^{1}$, Th. Wichert ${ }^{1}$, \\ and the ISOLDE Collaboration
}

\begin{abstract}
Using the radioactive acceptor ${ }^{111} \mathrm{Ag}$ for perturbed $\gamma \gamma$-angular correlation (PAC) spectroscopy for the first time, defect complexes formed with Ag are investigated in the II-VI semiconductors CdTe, ZnTe, and ZnSe. The donors In, $\mathrm{Br}$ and the Te-vacancy were found to passivate Ag acceptors in CdTe via pair formation, which was also observed in In-doped ZnTe. In undoped or Sb-doped CdTe and in undoped $\mathrm{ZnSe}$, the PAC experiments indicate the compensation of Ag acceptors by the formation of double broken bond centres, which are characterised by an electric field gradient with an asymmetry parameter close to $\eta=1$. Additionally, a very large electric field gradient was observed in CdTe, which is possibly connected with residual impurities.
\end{abstract}

(IS 369)

Presented at the 9th International Conference on II-VI Compounds in Kyoto, Japan, November, 01-05, 1999

and accepted for publication in Journal of Crystal Growth

\footnotetext{
${ }^{1}$ FR 10.3, Technische Physik, Universität des Saarlandes, D-66041 Saarbrücken, Germany
} 


\section{Introduction}

Group I elements act as acceptors in II-VI semiconductors if they are incorporated on cation sites. The $p$-type conductivity, however, that is achievable by doping with group I elements, is strongly limited. Thus, for $\mathrm{Ag}$ in CdTe a maximum hole concentration of $2 \cdot 10^{16} \mathrm{~cm}^{-3}$ is obtained [1], although the solubility of $\mathrm{Ag}$ is much higher. The effective $p$-type doping with group I elements seems to be impeded by the formation of compensating intrinsic defects or by the incorporation of the group I elements at interstitial lattice sites, acting there as donors. Thus, Chamonal et al. and Monemar et al. [2,3] proposed that close pairs of substitutional $\mathrm{Ag}_{\mathrm{Cd}}$ acceptors and $\mathrm{Ag}_{\mathrm{i}}$ donors are formed which passivate each other. A compensation mechanism that does not involve the presence of intrinsic defects was predicted by Park and Chadi on the basis of theoretical investigations [4,5] for various impurities in II-VI semiconductors. Here, self-compensation is effected by lattice relaxation and rebonding, transforming $50 \%$ of the acceptor impurities into donor-like defects, which are called AX- or double-broken-bond (DBB) centres.

In the past, information about the compensation of electrically active impurities in II-VI semiconductors was obtained using the donor probes ${ }^{111} \mathrm{In} /{ }^{111} \mathrm{Cd}$ or ${ }^{77} \mathrm{Br} /{ }^{77} \mathrm{Se}$ in perturbed $\gamma \gamma$ angular correlation experiments (PAC) $[6,7,8,9]$. Here, for the first time, the acceptor probe ${ }^{111} \mathrm{Ag} /{ }^{111} \mathrm{Cd}$ is used for PAC experiments that investigate the incorporation and complex formation of $\mathrm{Ag}$ atoms in $\mathrm{CdTe}, \mathrm{ZnTe}$, and $\mathrm{ZnSe}$. The PAC data yield information about the lattice site of $\mathrm{Ag}$ and the nature of defects that form complexes with the probe ${ }^{111} \mathrm{Ag}$. Thereby, the probe ${ }^{111} \mathrm{Ag}$ acts as acceptor if it is incorporated substitutionally on cation sites, or as donor if it is incorporated at interstitial sites. In this paper, results about the incorporation of ${ }^{111} \mathrm{Ag}$ into II-VI semiconductors and its interaction with defects are reported.

\section{Experimental procedure}

The ${ }^{111} \mathrm{Ag}$ probe atoms were implanted at the mass separator ISOLDE at CERN with an energy of $60 \mathrm{keV}$ into CdTe crystals, which were nominally undoped or pre-doped with $\mathrm{In}, \mathrm{Br}$, or Sb, into In-doped ZnTe, and into undoped ZnSe crystals. One of the undoped CdTe crystals was doped with In by diffusion after the implantation of ${ }^{111} \mathrm{Ag}$. In order to investigate the possible passivation of $\mathrm{Ag}$ acceptors by hydrogen, an undoped CdTe crystal was treated in a hydrogen plasma after implantation of ${ }^{111} \mathrm{Ag}$.

In a PAC experiment, the site fractions of the probe atoms in specific local configurations are quantitatively detected. In the present experiments, the environment of the ${ }^{111} \mathrm{Ag}$ probe atoms is of interest: whether they are incorporated on undisturbed or at relaxed substitutional sites, bound in pairs with donor-like defects, or whether they are incorporated as interstitial donors bound in pairs with acceptor-like defects. The different local configurations are distinguished by the different electric field gradients (EFG), which are measured at the daughter isotope ${ }^{111} \mathrm{Cd}$. The EFG tensor is usually expressed by the quadrupole coupling constant $v_{\mathrm{Q}}=\mathrm{eQV} \mathrm{zz}_{\mathrm{zz}} / \mathrm{h}$ and the asymmetry parameter $\eta=\left(\mathrm{V}_{\mathrm{xx}}-\mathrm{V}_{\mathrm{yy}}\right) / \mathrm{V}_{\mathrm{zz}}$. A detailed description of the application of PAC spectroscopy in semiconductors can be found elsewhere [10,11]. 


\section{Results and Discussion}

The defect complexes discussed in the present work are listed in Table I along with their characteristic EFG. The fraction of ${ }^{111} \mathrm{Ag}$ atoms, located at lattice sites with cubic symmetry, ranges between 5\% and 60\% and seems to be larger in the donor doped than in the undoped or acceptor doped crystals. Single Ag acceptors on cation sites belong to this fraction, which is characterised by a zero EFG.

Table 1.Defect complexes observed in II-VI semiconductors with the probe ${ }^{111} \mathrm{Ag}$

\begin{tabular}{|c|c|c|c|c|}
\hline \multirow[t]{2}{*}{ material } & \multirow{2}{*}{$\begin{array}{c}\text { sample } \\
\text { preparation }\end{array}$} & \multicolumn{2}{|c|}{ EFG } & \multirow{2}{*}{$\begin{array}{c}\text { proposed } \\
\text { defect }\end{array}$} \\
\hline & & $v_{\mathrm{Q}}$ & $\eta$ & \\
\hline \multirow[t]{3}{*}{ CdTe } & $\mathrm{T}_{\mathrm{A}}=700 \mathrm{~K}+\mathrm{Cd}$ & $59(2) \mathrm{MHz}$ & $0.9(1)$ & DBB \\
\hline & $\mathrm{T}_{\mathrm{A}}=430 \mathrm{~K}$ & $430(5) \mathrm{MHz}$ & $0.0(1)$ & $?$ \\
\hline & H plasma & $132(2) \mathrm{MHz}$ & $0.0(1)$ & $\mathrm{Ag}_{\mathrm{Cd}}-\mathrm{V}_{\mathrm{Te}}$ \\
\hline \multirow[t]{2}{*}{ CdTe:Br } & $\mathrm{T}_{\mathrm{A}}=650 \mathrm{~K}$ & $132(2) \mathrm{MHz}$ & $0.0(1)$ & $\mathrm{Ag}_{\mathrm{Cd}}-\mathrm{V}_{\mathrm{Te}}$ \\
\hline & $\mathrm{T}_{\mathrm{A}}=650 \mathrm{~K}$ & $259(5) \mathrm{MHz}$ & $0.0(1)$ & $\mathrm{Ag}_{\mathrm{Cd}}-\mathrm{Br}_{\mathrm{Te}}$ \\
\hline \multirow[t]{2}{*}{ CdTe:In } & $\mathrm{T}_{\mathrm{A}}=800 \mathrm{~K}+\mathrm{Cd}$ & $132(2) \mathrm{MHz}$ & $0.0(1)$ & $\mathrm{Ag}_{\mathrm{Cd}}-\mathrm{V}_{\mathrm{Te}}$ \\
\hline & $\mathrm{T}_{\mathrm{A}}=650 \mathrm{~K}+\mathrm{Te}$ & $62(3) \mathrm{MHz}$ & $0.0(2)$ & $\mathrm{Ag}_{\mathrm{Cd}}-\mathrm{In}_{\mathrm{Cd}}$ \\
\hline CdTe:Sb & $\mathrm{T}_{\mathrm{A}}=650 \mathrm{~K}+\mathrm{Cd}$ & 59(2) MHz & $0.9(1)$ & DBB \\
\hline ZnTe:In & $\mathrm{T}_{\mathrm{A}}=900 \mathrm{~K}+\mathrm{Te}$ & 63(2) MHz & $0.0(2)$ & $A g_{Z n}-I_{Z n}$ \\
\hline ZnSe & $\mathrm{T}_{\mathrm{A}}=900 \mathrm{~K}+\mathrm{Se}$ & $105(2) \mathrm{MHz}$ & $1.0(1)$ & DBB \\
\hline
\end{tabular}

a) Intrinsic defects in CdTe

A defect complex characterised by an axially symmetric EFG with $v_{\mathrm{Q}}=132 \mathrm{MHz}$ is observed in undoped CdTe after treatment in a hydrogen plasma and in CdTe crystals doped with In or $\mathrm{Br}$ donors (Fig. 1a). Since the occurrence of the EFG does not correlate with the respective extrinsic defect, an intrinsic defect is concluded to be responsible for the detected EFG. The donor-like interstitial $\mathrm{Cd}_{\mathrm{i}}$ atom paired with the $\mathrm{Ag}_{\mathrm{Cd}}$ acceptor seems to be unlikely. It can be expected that a $\mathrm{Ag}_{\mathrm{Cd}}-\mathrm{Cd}_{i}$ pair is unstable, since the constituents exchange their lattice sites, thereby releasing an interstitial $\mathrm{Ag}_{\mathrm{i}}$ donor. In contrast, the donor-like Te vacancy should form stable $\mathrm{Ag}_{\mathrm{Cd}}-\mathrm{V}_{\mathrm{Te}}$ pairs. On the basis of EPR investigations the Te vacancy was reported to be present in CdTe crystals doped with group III or group VII donors after annealing at temperatures between 650 and $1050 \mathrm{~K}$ [12]. Therefore, in the samples investigated here, the Te vacancy can be expected to be present, too, and is assigned to the observed EFG. The observation of the same EFG after hydrogen charging of a nominally undoped crystal and in crystals doped with In or Br donors suggests that the undoped CdTe becomes n-type after treating in hydrogen plasma. There have been no indications of H-passivated Ag acceptors, even if the sample was cooled to $12 \mathrm{~K}$ during the PAC measurement.

Following implantation of ${ }^{111} \mathrm{Ag}$ in some undoped CdTe crystals, a defect is observable that is characterised by an axially symmetric EFG with $v_{Q}$ about $430 \mathrm{MHz}$ (Fig. 1b). The unusually high magnitude of the EFG reminds of the EFG observed after hydrogen 
passivation of the acceptor probe ${ }^{111} \mathrm{In} /{ }^{111} \mathrm{Cd}$ in $\mathrm{Si}$ and $\mathrm{Ge}$ or of the acceptor probe ${ }^{111 \mathrm{~m}} \mathrm{Cd} /{ }^{111} \mathrm{Cd}$ in III-V semiconductors [11]. In CdTe, hydrogen may be present near the surface as a consequence of humidity of the air or of etching of the crystal. The magnitude of the EFG, therefore, may indicate that hydrogen atoms, passivating the $\mathrm{Ag}$ acceptors, are responsible for the observed EFG. This interpretation, however, seems to be problematic, since (i) the defect is still observable after thermal treatment of CdTe at temperatures above $600 \mathrm{~K}$, (ii) in $\mathrm{CdTe}$, the isotope ${ }^{111} \mathrm{Cd}$, used for the detection of the $\mathrm{EFG}$, is a host atom and does not bind a hydrogen atom after the radioactive decay of the ${ }^{111} \mathrm{Ag}_{\mathrm{Cd}}$ probe atom, and (iii) the defect is not observed in CdTe treated in a $\mathrm{H}$ plasma. Thus, the final identification of the respective defect generating this EFG will be subject of future investigations. Its occurrence in nominally undoped material, however, may point out to residual impurities.

b) Donor-acceptor pairs in CdTe and ZnTe

The formation of donor-acceptor pairs between the ${ }^{111} \mathrm{Ag}$ acceptor and donor impurities is observed in CdTe crystals doped with $\mathrm{In}$ or $\mathrm{Br}$ donors and in ZnTe doped with In donors. The Br-doped CdTe crystal shows an axially symmetric EFG with $v_{Q}=259 \mathrm{MHz}$ after implantation of ${ }^{111} \mathrm{Ag}$ and subsequent annealing at $650 \mathrm{~K}$ (Fig. 2a). The axial symmetry is expected for the formation of close $\mathrm{Ag}_{\mathrm{Cd}}-\mathrm{Br}_{\mathrm{Te}}$ pairs. The assignment of the EFG to $\mathrm{Ag}_{\mathrm{Cd}}-\mathrm{Br}_{\mathrm{Te}}$ pairs is strongly supported by EFG calculations yielding an EFG with $v_{\mathrm{Q}}=267 \mathrm{MHz}$ at the site of the ${ }^{111} \mathrm{Ag} /{ }^{111} \mathrm{Cd}$ probe that is caused by a neighbouring $\mathrm{Br}_{\mathrm{Te}}$ donor [13].
$\mathrm{R}(\mathrm{t})$
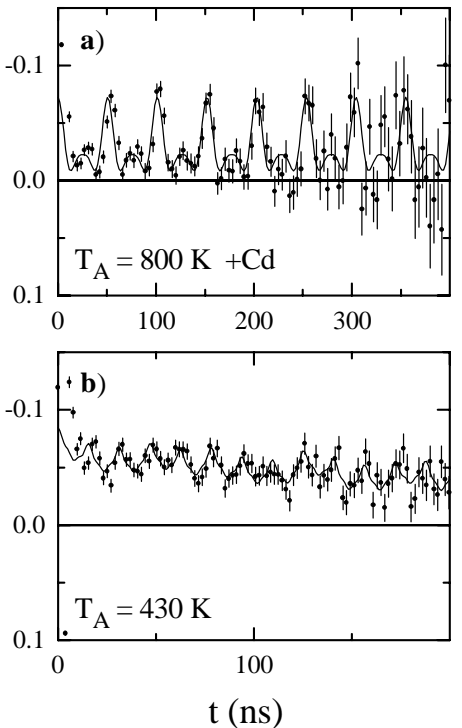

Fig. 1: PAC spectra of CdTe crystals implanted with ${ }^{111} \mathrm{Ag}$ : a) the formation of a ${ }^{111} \mathrm{Ag}-V_{T e}$ pair in In-doped CdTe and b) a defect possibly connected with residual impurities.
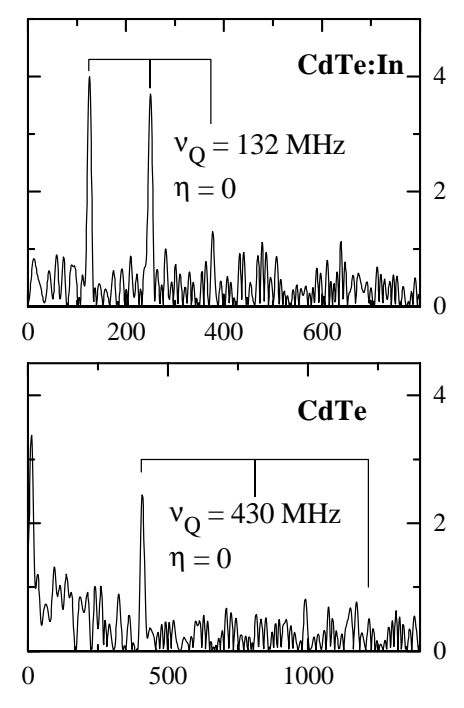

$\omega(\mathrm{Mrad} / \mathrm{s})$
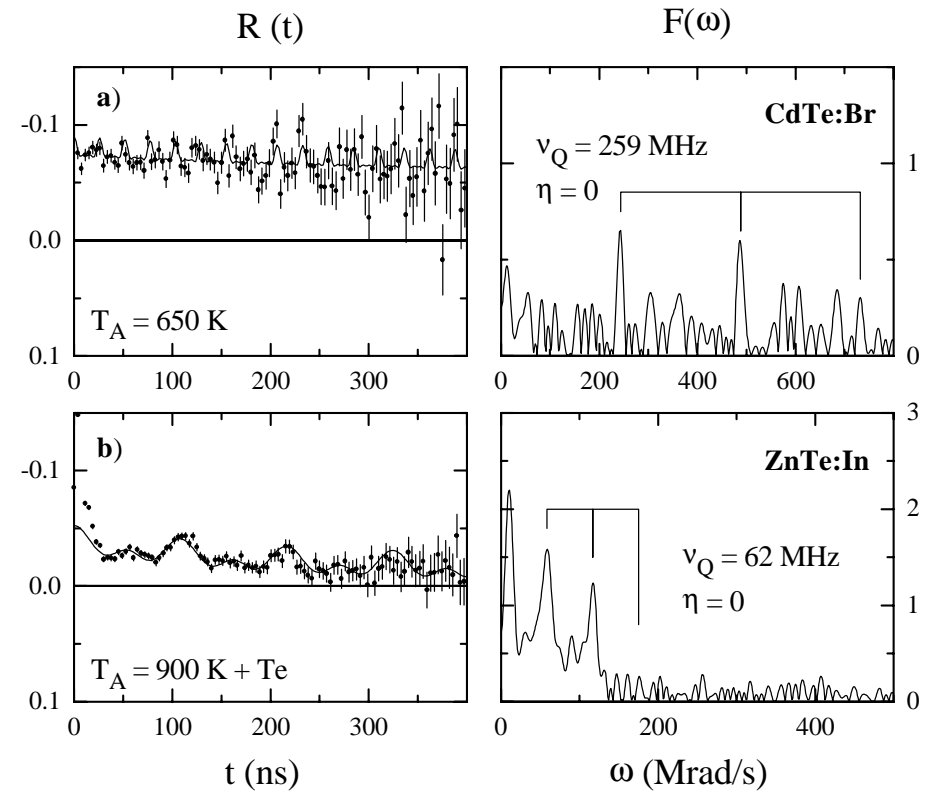

Fig. 2: PAC spectra showing the formation of pairs between the ${ }^{111} \mathrm{Ag}$ acceptor and a) $\mathrm{Br}$ donors in $\mathrm{CdTe}: \mathrm{Br}$ and $b)$ In donors in MOCVD grown ZnTe:In. 
In CdTe crystals implanted with ${ }^{111} \mathrm{Ag}$ and diffused with $\mathrm{In}$ at $880 \mathrm{~K}$, a defect complex is observed, characterised by an almost axially symmetric EFG $(\eta \leq 0.1)$ with $v_{Q}=62 \mathrm{MHz}$ [14]. The identical EFG is observed in CdTe:In grown by MOCVD, subsequently implanted with ${ }^{111} \mathrm{Ag}$ and annealed under Te pressure at $650 \mathrm{~K}$. The EFG is not observed in CdTe crystals containing no In donors. Therefore, the defect complex is assigned to the donoracceptor pair $\mathrm{In}_{\mathrm{Cd}^{-}}{ }^{111} \mathrm{Ag}_{\mathrm{Cd}}$. The EFG is close to $v_{\mathrm{Q}}=56.6 \mathrm{MHz}(\eta=0.07)$, which was measured with the donor probe ${ }^{111} \mathrm{In}_{\mathrm{Cd}}$ in CdTe doped with $\mathrm{Ag}_{\mathrm{Cd}}$ acceptors [14]. In both cases, primarily the $\mathrm{In}_{\mathrm{Cd}}-\mathrm{Ag}_{\mathrm{Cd}}$ pair is formed and the EFG is measured at the host atom ${ }^{111} \mathrm{Cd}$. In case of the probe ${ }^{111} \mathrm{Ag}$, however, the $\mathrm{EFG}$ originates from the isolated $\mathrm{In}_{\mathrm{Cd}}$ donor, whereas in case of the probe ${ }^{111}$ In the EFG originates from the isolated $\mathrm{Ag}_{\mathrm{Cd}}$ acceptor. The small difference between the EFG measured for the $\mathrm{In}_{\mathrm{Cd}}$ donor and the $\mathrm{Ag}_{\mathrm{Cd}}$ acceptor is in good agreement with preliminary calculations of the defect specific EFG. A defect complex is also observed in ZnTe crystals, which were doped with In donors during MOCVD growth. Since the EFG with $v_{Q}=62 \mathrm{MHz}$ and $\eta \leq 0.1$ (Fig. 2b) is very close to that measured in Indoped CdTe crystals, the defect complex is assigned to the $\mathrm{In}_{\mathrm{Zn}}-\mathrm{Ag}_{\mathrm{Zn}}$ pair. The similar magnitudes of the EFG corresponding to the In-Ag pairs in CdTe and ZnTe are plausible, since in both materials the nearest neighbour shell about the probe atom consists of Te atoms.

c) Double-broken-bond centres in CdTe and $\mathrm{ZnSe}$

In undoped and in Sb-doped CdTe crystals, annealed under Cd pressure, an EFG is observed (Fig. 3a), which is characterised by $v_{\mathrm{Q}}=59 \mathrm{MHz}$ and the large asymmetry parameter $\eta=0.9$. In Sb-doped CdTe no indications of an additional EFG are observed, which can be correlated with the presence of $\mathrm{Sb}_{\mathrm{Te}}$ acceptors. The formation of $\mathrm{Ag}_{\mathrm{i}}-\mathrm{Sb}_{\mathrm{Te}}$ pairs, in principle possible, obviously does not take place with a detectable fraction of ${ }^{111} \mathrm{Ag}$ atoms (i.e. with at least $5 \%$ ). An EFG with an asymmetry parameter close to $\eta=1$ is also observed in undoped ZnSe after implantation of ${ }^{111} \mathrm{Ag}$ and subsequent annealing at $900 \mathrm{~K}$ under Se pressure (Fig. 3b). The coupling constant $\mathrm{v}_{\mathrm{Q}}=105 \mathrm{MHz}$ is significantly larger than in CdTe.

The occurrence of the defect complex in undoped $\mathrm{CdTe}$ and $\mathrm{ZnSe}$ suggests that an intrinsic defect has formed a pair with the $\mathrm{Ag}_{\mathrm{Cd}}$ acceptor. Interstitial $\mathrm{Cd}$ atoms are excluded because of the instability of the formed pair, as outlined above. Since the defect is observed likewise in undoped and acceptor doped crystals, the Te vacancy might be considered, which, now, would be twofold positively charged, assuming that in the donor doped crystals the neutral or singly charged $\mathrm{Te}$
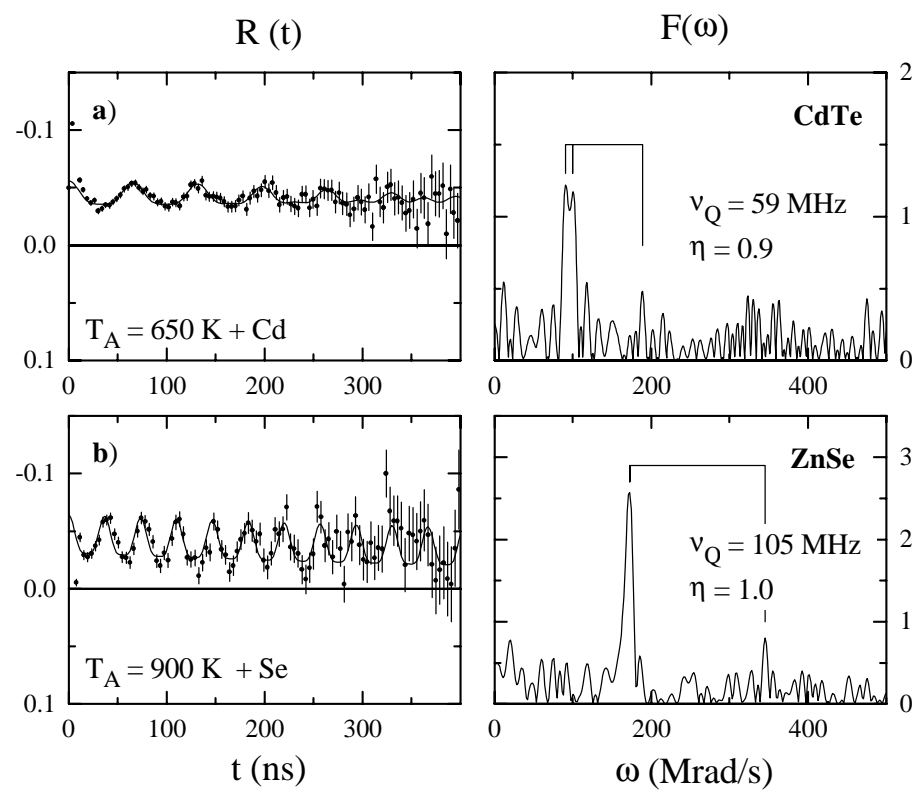

Fig. 3. PAC spectra indicating the compensation of the ${ }^{111} \mathrm{Ag}$ acceptor by the formation of double-brokenbond centres in a) CdTe and b) ZnSe. 
vacancy is observed (see Fig. 1a). The strong asymmetry parameter might point to a strong relaxation about the Te vacancy, giving rise to a complex with low symmetry. A relaxation, however, giving rise to a low symmetry should not be expected in case of the twofold positively charged Te vacancy, since at the neighbouring $\mathrm{Cd}$ atoms no dangling bonds are occupied. Instead, the large asymmetry parameter might point to a defect complex consisting of two chalcogen vacancies trapped by the ${ }^{111} \mathrm{Ag}_{\mathrm{M}}$ acceptor. Since in CdTe the observed defect is not removed by annealing under Te pressure and in $\mathrm{ZnSe}$ the defect is generated after annealing under Se pressure, also this complex is excluded.

For the compensation of donors and acceptors in

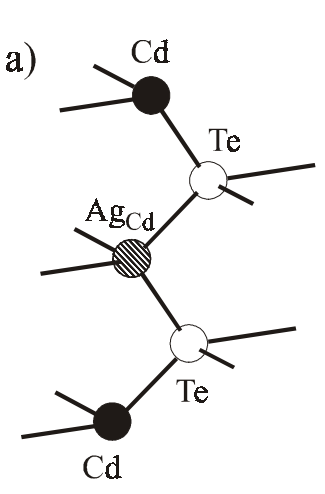

acceptor state

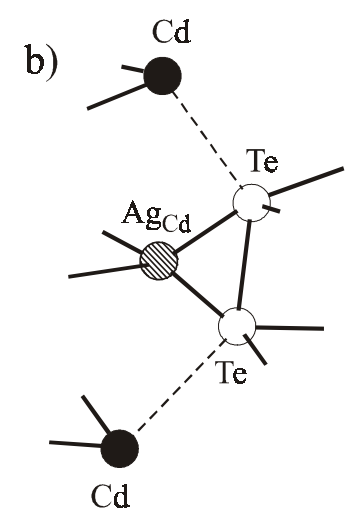

DBB state

Fig. 4. Substitutional incorporation of Ag in CdTe as a) shallow acceptor and b) donor-like defect in the double-brokenbond centre $(D B B)$ according to ref. [4, 5].

II-VI semiconductors, no additional defect is required if the mechanism discussed by Park and Chadi takes place [4,5]. Unfortunately, the authors did not discuss the case of group I acceptors. If one transfers their model to the case of a Ag acceptor (see Fig. 4), there are two possible local relaxations to be considered, whereby one has trigonal symmetry about the impurity atom and, therefore, would generate an axially symmetric EFG. For the second, the so called DBB centre, however, an asymmetry parameter close to $\eta=1$ at the site of the ${ }^{111} \mathrm{Ag}$ acceptor can be expected if a configuration like in Fig. $4 \mathrm{~b}$ has been formed, originating from the substitutional Ag acceptor (Fig. 4a). In this case, however, a mechanism is required that 'freezes' the local complex for at least $300 \mathrm{~ns}$ after the decay of the ${ }^{111} \mathrm{Ag}$ acceptor to the host atom ${ }^{111} \mathrm{Cd}$, used for recording the PAC spectrum. Such a timespan might be realistic, since the restoration of the lattice about the ${ }^{111} \mathrm{Cd}$ atom requires (i) two additional electrons, which have to be supplied by other impurity atoms, and (ii) the breakup of the Te-Te (Se-Se) bond. The DBB centre, therefore, seems to be a plausible interpretation of the observed EFG. It should be noted that there are six equivalent configurations of the DBB centre, which would average the EFG to zero, if sufficiently fast transition between these configurations occurred. Such a transition, however, involves the rearrangement of six electrons so that the transition time might be out of the $300 \mathrm{~ns}$ time window used for the PAC experiment.

\section{Conclusions}

Using the probe ${ }^{111} \mathrm{Ag} /{ }^{111} \mathrm{Cd}$, information about the compensation of acceptor impurities in II-VI semiconductors is obtained. Pairing of the acceptors Ag with intrinsic defects, like the chalcogen vacancy, and extrinsic defects, like In and $\mathrm{Br}$ donors, is observed. In addition, in $\mathrm{CdTe}$ and $\mathrm{ZnSe}$, indications for the compensation of Ag acceptors by the formation of DBB centres exist. Finally, in CdTe a defect is detected, which might be connected with residual impurities. 


\section{Acknowledgements}

The financial support by the BMBF, grant No. WI04SAA, is gratefully acknowledged. It is a pleasure to thank K. Freitag (Universität Bonn), M. Deicher (Universität Konstanz), R. Grötzschel and U. Hornauer (FZ Rossendorf) for implanting crystals.

\section{References}

[1] J.P. Chamonal, E. Molva, J.L. Pautrat, Solid State Comm. 43 (1982) 801.

[2] J.P. Chamonal, E. Molva, J.L. Pautrat, L. Revoil, J. Cryst. Growth 59 (1982) 297.

[3] B. Monemar, E. Molva, Le Si Dang, Phys. Rev. B 33 (1986) 1134.

[4] C.H. Park, D.J. Chadi, Phys. Rev, Lett. 75 (1995) 1134.

[5] D.J. Chadi, Phys. Rev. B 59 (1999) 15181.

[6] Th. Wichert, Th. Krings, H. Wolf, Physica B 185 (1993) 297.

[7] H. Wolf, A. Jost, R. Lermen, T. Filz, V. Ostheimer, Th. Wichert, Materials Science Forum 196-201 (1995) 321.

[8] V. Ostheimer, A. Jost, T. Filz, St. Lauer, H. Wolf, Th. Wichert, Appl. Phys. Lett. 69 (1996) 2840.

[9] H. Wolf, T. Filz, J. Hamann, A. Jost, V. Ostheimer, Th. Wichert in:

Shallow Level Centers in Semiconductors, Eds C.A.J. Ammerlaan and B. Pajot, (World Scientific, Singapore, 1997) p. 123.

[10] Th. Wichert, M. Deicher, G. Grübel, G. Keller, N. Schulz, H. Skudlik, Appl. Phys. A 48 (1989) 59.

[11] Th. Wichert, in: Identification of Defects in Semiconductors, Ed. M. Stavola (Academic Press, London, 1999) vol. 51B p. 297, and references therein.

[12] B.K. Meyer and D.M. Hofmann, Appl. Phys. A 61 (1995) 213.

[13] S. Lany, P. Blaha, V. Ostheimer, H. Wolf, Th. Wichert, to be published.

[14] H. Wolf, T. Filz, J. Hamann, V. Ostheimer, S. Lany, Th. Wichert, M. Deicher, A. Burchard, ISOLDE Collaboration, Mat. Res. Soc. Symp. Proc. 510 (1998) 337. 